\title{
LEITURAS FENOMENOLÓGICAS DA HERMENÊUTICA HEIDEGGERIANA EM “A HORA DA ESTRELA", DE CLARICE LISPECTOR
}

\author{
PHENOMENOLOGICAL READINGS OF HEIDEGGERIAN HERMENEUTICS \\ IN “THE HOUR OF THE STAR”, BY CLARICE LISPECTOR
}

Cacio José Ferreira 1

Norival Bottos Júnior 2

Recebido: 22 fev. 2019

Aceito: 05 jun. 2019

DOI https://doi.org/10.29327/2.1373.1-8

\begin{abstract}
RESUMO: O presente texto discute os conceitos fenomenológicos da hermenêutica heideggeriana presentes em A hora da estrela (1998), de Clarice Lispector, estabelecendo relação entre o narrador Rodrigo e a personagem Macabéa. A intenção é identificar como o dasein se manifesta, presente em Rodrigo, o que lhe permite a compreensão de si e do outro. A partir disso, busca-se a análise da construção narrativa que surge de forma (pré) ontológica, diferenciando o ôntico, o ontológico e o pré-ontológico. Através dos conceitos de facticidade, cura e o nada, verificar-se-á que Rodrigo interpretar o modo de existir da personagem Macabéa como uma possibilidade de ser. Para que o dialogo aconteça, o estudo crítico prevê o entendimento de alguns termos básicos da fenomenologia heideggeriana, como: ente, ser, facticidade, cura e o nada. $\mathrm{O}$ estudo fará a relação entre a existência e o existencial, revelando os aspectos que diferenciam o dasein dos demais entes.
\end{abstract}

PALAVRAS-CHAVE: Dasein; Existencialismo; Hermenêutica; A hora da estrela; Clarice Lispector.

ABSTRACT: This article deal with the phenomenological concept of the novel in The hour of the star (1998), by Clarice Lispector, which compare the character narrator Rodrigo and the character Macabéa. The propose is identify the dasein's modes of being concerning the character Rodrigo which permit him to understand himself and the others. Through theses conceptions we will analyze the construction of the narrative which appears pre-ontological way, blowing in the wind and point the difference among the ontical, ontological and pre-ontological. Through the concept of facticity, cure and nothingness we will present that Rodrigo interprets the modes of existence of Macabéa as

\footnotetext{
1 Doutorando em Literatura pela Universidade de Brasília (UnB). Docente na Universidade Federal do Amazonas (UFAM). E-mail: caciosan@hotmail.com ORCID iD https://orcid.org/0000-0003-0009-226X

2 Doutor em Letras e Linguística pela Universidade Federal de Goiás (UFG). Docente na Pontifícia Universidade Católica de Goiás (PUC/GO). E-mail: nonobottos@gmail.com ORCID iD https://orcid.org/0000-0002-2339-7536
} 
a possibility of being. This paper requires knowledge of the Heidegger's concept as: 'ente', being, facticity, cure and nothingness. This study will demonstrate the relationship among the existence and the existential showing the aspects which differ the dasein over the others 'ente' inside of the corpus.

KEYWORDS: Dasein; Existentialism; Hermeneutic; The hour of the star; Clarice Lispector.

\section{CONSIDERAÇÕES INICIAIS}

Nada agrada mais, em relação a natureza filosófica da escrita de Clarice Lispector, nem por mais tempo, do que a tentativa quase incessante de representação justa que a autora de origem ucraniana faz da natureza geral da filosofia e seu amálgama com a característica particularizante da literatura. Nesse sentido, para Wendel Santos:

Não sendo uma forma de criação, o lírico funda a forma da diç̧ão. Em vez de produzir uma transfiguração na linguagem, atravessando-a com a diversidade ontológica do mundo real e do mundo imaginário, o lírico transforma o mundo não em outro mundo ${ }^{3}$, mas em um mundo do sujeito. A natureza do mundo do sujeito não é diversa da natureza do mundo existente. Isto é: o lírico não diz o mundo imaginário como uma necessidade epistemológica; ele diz imaginariamente o próprio mundo do sujeito (SANTOS, 1983, p. 66).

Dessa maneira, poesia e vida não representam a mesma coisa, o lírico não cria um universo inédito, a mímesis ${ }^{4}$ é parte fundamental da ficção ao fazer emergir uma nova perspectiva na vida. Entretanto, o lírico só mantém compromisso com a linguagem sem conexão imediata com o mundo. Há um imperativo na arte que afirma que a vida não é suficiente, pois a vida como obra de arte não deu certo historicamente. A apropriação do lírico pela prosa é o imperativo da reflexão sobre o ser frente às novas dinâmicas do mundo. A arte ficcional como representação é importante porque não há meio de evitar que ela seja uma grande reflexão sobre a vida, por isso é seu dever que tudo seja mimetizado pela prosa.

\footnotetext{
3 Grifo do autor.

${ }^{4}$ Grifo nosso.
} 
A não ser que a vida entrasse numa espécie de êxtase contínuo, resta à linguagem a tarefa de mediar essas duas partes - a filosofia e a literatura - que formam o indefinido no homem. Nesse sentido, para Martin Heidegger o uso cotidiano da linguagem encobriu o que há de essencial na relação entre a arte e a vida, especialmente na poesia lírica.

Por conseguinte, Clarice Lispector, dona de uma prosa que tenta a todo tempo fazer esboroar a separação entre prosa e poesia lírica, de suspender a diferença ontológica da filosofia e a experiência mimética da literatura, ampliam essas formas de pensamento que se completam e se mesclam. A relação muito generalizante da filosofia se deixa envolver, nos seus escritos literários, numa forma de tornar muito imediato o que há na vida. Também imediatiza o que há nela, mas de outra forma, a partir daí a linguagem se renova sem renunciar a seu "estar-aí" no mundo (dasein) 5 .

$\mathrm{Na}$ literatura filosófica de Clarice Lispector, é necessário lançar o olhar ontológico para o mundo não como uma descoberta, mas como uma gratidão, por isso a Fenomenologia de Martin Heidegger impregna o texto clariciano, pois trata-se de uma prática afetiva, assim, arte e filosofia ganham forma na potência do ato criativo, como sugere a defesa nietzschiana de Giorgio Agamben sobre o tema da relação entre arte e filosofia. Para o filósofo italiano, uma estética destituída de seu caráter político e ético, uma arte destinada à fruição puramente desinteressada das coisas, ou seja, num ato contemplativo, estéril. Significa inferir que toda techné, a tradição envolvida entre o comprometimento histórico e ético, os padrões que essa tradição outorgou à humanidade seja abandonada em nome da aventura do novo e de uma prática que não mais se converta em práxis, mas em barbárie. Para Giorgio Agamben, que foi aluno de Martin Heidegger, “o novo é a admissão do passado" (AGAMBEN, 2009, p. 67).

O questionamento do ser, retomado por Heidegger, só foi possível com o rompimento dos preconceitos que estavam ao redor da concepção tradicional do ser. O rompimento com a tradição permite a criação de novos termos, para a busca da compreensão do ser, procura que se encontra presente na obra corpus. Para compreender a perquirição pelo ser em A hora da estrela (1998), é necessário esclarecer os termos heideggerianos para análise do texto de Clarice Lispector. Alguns dos termos a serem esclarecidos são: ser, ente e dasein. Esses termos estão ligados a uma nova

\footnotetext{
5 Termo utilizado por Heidegger como forma de definição do ser humano.
} 
reflexão que se diferencia da ontologia tradicional grega que permeava a filosofia ocidental. Na ontologia tradicional o ser e ente não estão distintos, mas são considerados únicos. Nessa ontologia, não é possível a distinção desses termos, tudo que é "é".

Com a ontologia heideggeriana há uma ruptura com a ontologia tradicional. Tal fratura se mostra na separação do ser e ente, termos que serão abordados adiante. E a partir desses termos, os conceitos de (pré) ontológico, ontológico e ôntico (termo criado por Heidegger) tornam-se apreensíveis. Ainda, quais as relações entre o ser, o ente, e o dasein, explicando o termo dasein, e o que o torna um ente especial, quais são os modos de ser que o torna peculiar, e qual a sua relação com a facticidade e cura.

Primeiro, pretende-se desenvolver uma relação entre a obra e os termos citados acima. Tal como Rodrigo, de A hora da estrela (1998), faz uso de seu ser, e como busca compreender a si mesmo, mostrando modos pertencentes ao dasein (ser do homem), e como ele compreende os entes que compõem o "seu" mundo, e ainda, como se projeta no mundo, ou seja, uma forma de facticidade. A partir da compreensão de si mesmo, Rodrigo passa a “captar" a história de Macabéa e o desenvolvimento de sua narrativa. Há diferença entre a facticidade de Rodrigo e Macabéa. Ele se joga no mundo e projeta-se, diferenciando de Macabéa que permanece sem um projeto que a leve a autenticidade.

Nessa perspectiva, para romper com a ontologia tradicional, Heidegger vai retomar o questionamento do ser. Esse questionamento se diferencia de "um questionário simples" (HEIDEGGER, 2012, p. 40), nisso é quebrada uma série de preconceitos acerca do ser. Esses preconceitos, que se formaram ao longo da história ocidental, enfatizam a busca pela aletheia, ou seja, o desvelamento do ser que estava encoberto e se tornou uma "evidência", o que era busca natural do ser humano pré-socrático, uma convivência natural com a verdade do ser, se tornou algo ao longo da história, dominada pelo viés da razão e o cogito perdeu seu sentido natural e, com isso, perdeu-se também a relação íntima com a coisa. O simples questionar sobre o ser e o sentido de ser tornou-se algo que não poderia ser interpelado, porque aquilo se diz sobre o ser, ou ainda, o seu uso cotidiano na sua compreensão verbal, acabou velando e relegando ao esquecimento a sua verdadeira essência ontológica. 


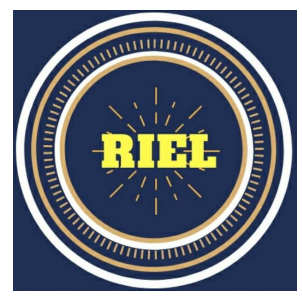

Em Sócrates via Platão, temos o marco inicial da filosofia ocidental e com ela o domínio da razão, o logos e da verdade das coisas e não do ser. O Ser Absoluto e o Mundo das Ideias, concebidos pela teoria platônica se tornam pilares para o fundamento da metafísica e, de um modo mais amplo, altera o modo de compreensão do ser das coisas, inclusive, do conhecimento científico.

O Ser Absoluto e o Mundo das Ideias, ou seja, a compreensão de que somente tais entidades correspondam aquilo que verdadeiramente é, representam a entificação do ser de forma absoluta. Essa entificação do ser é fonte que emana nos seres das coisas e passa a representá-las a partir de uma verdade atemporal e a-histórica. Essa é a concepção presente na alegoria da caverna, onde o mundo sensível se apresenta como uma representação do Mundo das Ideias, aquilo que verdadeiramente é, como se vê no trecho abaixo:

- Meu caro Glauco, este quadro - continuei - deve agora aplicar-se a tudo quanto dissemos anteriormente, comparando o mundo visível através dos olhos à caverna da prisão, e a luz da fogueira que lá existia à força do Sol. Quanto à subida ao mundo superior e à visão do que lá se encontra, se a tomares como a ascensão da alma ao mundo inteligível, não iludirás a minha expectativa, já que é teu desejo conhecê-la. O Deus sabe se ela é verdadeira. Pois, segundo entendo, no limite do cognoscível é que se avista, a custo, a ideia do Bem; e, uma vez avistada, compreende-se que ela é para todos a causa de quanto há de justo e belo; que, no mundo visível, foi ela que criou a luz, do qual é senhora da verdade e da inteligência, e que é preciso vê-la para se ser sensato na vida particular e pública. [...] A presente discussão indica a existência dessa faculdade na alma de um órgão pelo qual aprende; como um olho que não fosse possível voltar das trevas para a luz, senão juntamente com todo o corpo, do mesmo modo esse órgão deve ser desviado, juntamente com a alma toda, das coisas que se alteram, até ser capaz de suportar a contemplação do Ser e da parte mais brilhante do Ser (PLATÃO, 2007, p. 212-214).

A compreensão do ser se dá de forma genérica, dando ao homem a razão como característica única que o diferencia dos animais, característica presente no cogito sum de Descartes. Nessa compreensão cristalizada, o homem passa a ser dominado por uma característica genérica, a razão, o logos. Essa descoberta como ser racional, ou seja, o homem como ser capaz de racionalizar sua existência, foi base para nossa sociedade técnica, negando todas as outras possibilidades de ser do homem. Essa forma genérica de compreender as coisas e o homem foi abalada definitivamente com o martelar de Nietzsche sobre as bases da metafísica tradicional. Sua 
filosofia abarcou toda a trajetória ocidental e estava encoberta por fundamentos cristalizados, não permitindo o retornar da fenomenologia husserliana.

Nietzsche pôs em questão a metafísica e seus fundamentos dogmáticos, propondo uma amoralidade filosófica. Assim, tudo é passivo de ser questionado, possibilitando novas formas de ver e de fazer filosofia. Como na passagem a seguir:

E a ciência, aguilhoada por sua poderosa ilusão, se lança então irresistivelmente até seus limites, onde acaba encalhando e quebrando seu otimismo latente inerente à essência da lógica. De fato, a circunferência do círculo da ciência é composta por um número infinito de pontos e, embora seja ainda impossível conceber um círculo inteiro poderia ser medido, o homem superior e inteligente atinge fatalmente, antes mesmo de ter completado a metade da sua vida, certos pontos extremos da circunferência, onde permanece detido diante do inexplicável. Quando, cheio de espanto, vê nesse extremo a lógica se enrola sobre si mesma como uma serpente e morder-se a cauda - então surge diante dele a forma nova do conhecimento, o conhecimento trágico, do qual lhe é impossível suporta unicamente o aspecto, sem a proteção e o auxílio da arte (NIETZSCHE, 2001, p. 109)

A sociedade técnica moderna não prevê a verdade da arte porque as duas entidades supremas do fazer artístico e o caráter apolíneo e dionisíaco não estão mais em harmonia na terra. A sociedade contemporânea, a herdeira do pensamento platônico socrático, impõe a verdade do logos. Assim, para Nietzsche, a razão não satisfaz as necessidades humanas.

Heidegger propõe em Ser e Tempo (2012) uma retomada ao questionamento do ser. Esse questionamento possui estruturas que o diferencia de uma simples interpelação. É uma busca que no próprio questionar já se compreende de forma "inapreensível” o que se busca, isto é, o questionamento do ser possui em si mesmo a transparência orientadora que conduz ao sentido do ser. No questionar teremos o "questionar acerca de alguma coisa, questionar acerca de... [...] um interrogar sobre..." (HEIDEGGER, 2012, p. 40), respectivamente teremos o questionado e o interrogado. O questionado é o que se está em questão, nesse caso é o ser; o interrogado é o quem está direcionado, endereçado à questão, o ente.

E ainda temos o perguntado, a meta do questionamento, ou seja, o sentido de ser. Para que esse questionamento tornasse possível, foi necessário a desentificação do ser, como já mencionado, o ser estava entificado na concepção de Ser Absoluto e Mundo das Ideias, o ser não é mais outro 


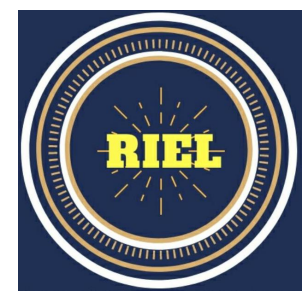

ente, mas sim o movimento verbal. Ente é tudo que é exceção do próprio ser. Heidegger afirma que a compreensão que temos de ser é uma compreensão mediana verbal. Dessa forma, ser é o movimento de estar sendo, só se é sendo, ser também é o que termina o ente como ente. Em meio a esses entes, existe um ente especial que possui em seu ser os modos de ser, que possibilitam o questionamento. Visualizar, compreender, escolher e aceder são os modos. Heidegger (2010; 2012) conceitua esse ente de dasein. É a partir da compreensão do seu ser que o dasein possui acesso ao ser dos outros entes.

Caso a questão do ser deva ser colocada explicitamente e desdobrada em toda a sua transparência, a sua elaboração exige, de acordo com as explicações feitas até aqui, a explicitação da maneira de se visualizar o ser, de se compreender e apreender conceitualmente o sentido, a preparação da possibilidade de uma escolha correta do ente exemplar, a elaboração do modo genuíno de acesso a esse ente. Visualizar, compreender, escolher, aceder a suas atitudes constitutivas do questionar e, ao mesmo tempo, modos de ser de um determinado ente, daquele ente que nós mesmos, os que questionam, sempre somos. Elaborar a questão do ser significa, portanto, tornar transparente um ente - que questiona - em seu ser. Como modo de ser de um ente, o questionar dessa questão se acha essencialmente determinado pelo que nela se questiona - pelo ser. Designamos com o termo presença esse ente que cada um de nós mesmos sempre somos e que, entre outras coisas, possui em seu ser a possibilidade de questionar. A colocação explícita e transparente da questão sobre o sentido do ser requer uma explicação prévia e adequada de um ente (da presença) no tocante de seu ser (HEIDEGGER, 2012, p. 42-43).

A Compreensão do dasein não está isolada a si mesmo, mas a partir do ente mundo. Mundo aqui não se diz respeito a lugar (planeta, país, casa etc.) em que o dasein está inserido. Dasein não é como um simples ente que pode está dentro do mundo, como a roupa está dentro do guarda-roupa, por exemplo, mas o contrário. O dasein é in-sein, ser-em, isso não quer dizer que ele possui relações corpóreas ou espaciais. “A expressão 'sou' conecta-se a 'junto'; 'eu sou’ diz por sua vez: eu moro, detenho-me junto... ao mundo, como alguma coisa que, deste ou daquele modo me é familiar" (HEIDEGGER, 2012, p. 100).

Os entes que são desprovidos do dasein não possui o modo de ser-em (in-sein), e sim serdentro (sein-in) do mundo. É o ente que possui essa relação in-sein com este mundo familiar que é seu. Possui a capacidade de questionar sobre o sentido de ser e compreender não somente o seu ser como o ser dos outros entes. Este modo de ser do dasein, ser-em um mundo compreende os entes 


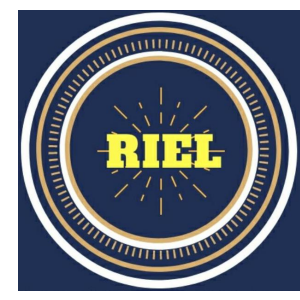

que estão dentro desse universo. Esses entes vêm ao encontro do dasein, lingando-se ao destino do dasein, como se vê na passagem a seguir:

Chamamos de facticidade o caráter de fatualidade do fato da presença em que, como tal, cada presença sempre é. À luz da elaboração das constituições existenciais básicas da presença, a estrutura complexa desta determinação ontológica só poderá ser apreendida em si mesma como problema. O conceito de facticidade abriga em si o ser-no-mundo de um ente "intramundano", de maneira que este ente possa ser compreendido como algo que, em seu "destino", está ligado aos entes que lhe vêm ao encontro dentro de seu próprio mundo (HEIDEGGER, 2012, p. 102).

Segundo Heidegger, a facticidade do ser-em é um ser-lançado-em um mundo, o dasein está lançado em um lugar que lhe é familiar, podendo este ficar no estado de lançamento, ou se projetar para numa outra possibilidade de ser. Esse projetar-se pela antecipação de si mesmo num já sendoem um mundo, esse anteceder é o que determina a cura, conforme postulação a seguir:

A expressão "cura" significa um fenômeno ontológico existencial básico que também em sua estrutura não é simples. A totalidade ontologicamente elementar da estrutura da cura não pode ser reconduzida a um "elemento primário" ôntico, assim como o ser não pode ser a ideia de ser "esclarecido" pelo ente. Por fim, há de se mostrar que a ideia de ser é tão pouco "simples" como o ser da presença. A determinação da cura, como anteceder-a-si-mesma-no-já-ser-em..., enquanto-serjunto-a, torna claro que esse fenômeno está, em si mesmo, articulando estruturalmente (HEIDEGGER, 2012, p. 263-264).

Rumando para o rompimento com ontologia clássica e a metafísica, a partir da compreensão desertificada do ente, a lógica, a razão ou o cogito sum, que até eram premissas que diferenciava o homem dos outros animais. Na fenomenologia heideggeriana, além da possibilidade de questionar e compreender o ser a partir do mundo que lhe é familiar, o ser do homem, ou dasein, possui a capacidade variada de interpretar previamente a si mesmo e o mundo, tornando possível compreender o homem em outras possíveis maneiras de ser. 


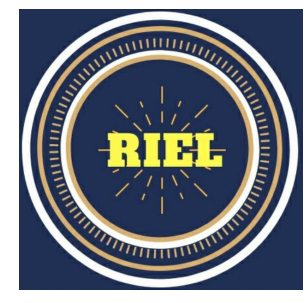

\section{LINGUAGEM COMO MUNDO FAMILIAR: O NARRADOR E A DATILÓGRAFA}

Retomando a obra A hora da estrela (1998), temos Rodrigo como narrador-escritorfictício. Tal processo permite que a narração se dê no momento em que a obra está sendo escrita, ou seja, o ato narrativo acontece no escrever de Rodrigo. E ao se tratar do próprio labor literário, desenvolve uma metalinguagem, já que no decorrer da narrativa o escritor fictício está escrevendo e descrevendo o próprio escrever. Rodrigo revela seu papel de escritor e como a obra vai se desvelando diante de si e trata das relações entre a obra e o escritor e o escritor e a personagem Macabéa. Essas relações podem ser compreendidas a obra como verdade, verdade que é alcançada pelos desvelamentos provocados pelo questionar e a independência da obra de seu autor, e como Rodrigo e Macabéa estão lançados em seus mundos familiares.

A narrativa desenvolve-se por meio de questões levantadas por Rodrigo. Questionamentos sobre ele, Macabéa e a obra, ou seja, a própria obra é uma pergunta: "Juro que este livro é feito sem palavras. É uma fotografia. Este livro é um silêncio. Este livro é uma pergunta” (LISPECTOR, 1998, p. 17). O questionamento é uma possibilidade que o dasein possui, para que possa, a partir daí, buscar o seu ser como ele é, e ser dos outros entes. É a partir da interpelação que Rodrigo antecipa o que sua obra será. O questionar é o guia para o ser da obra cujo desfecho está além de sua imaginação.

Por isso não sei se minha história vai ser - se o quê? Não sei de nada, ainda não me animei a escrevê-la. Terá acontecimentos? Terá. Mas quais? Também não sei. Não estou tentando criar em vós uma expectativa aflita e voraz: é que realmente não sei o que me espera (LISPECTOR, 1998, p. 22).

O questionamento o guia para a verdade da obra literária, possibilitando uma pequena abertura, um pequeno desvelamento (verdade) do ser da obra: "ainda outro modo como a verdade se torna verdade é o questionar do pensador que, como o pensar do Ser, o nomeia no seu ser digno de questionamento" (HEIDEGGER, 2010, p. 157), entretanto, contrapondo-o, também há o velado do ser da obra, o nada, o que ainda está encoberto, impossibilitando o artista conhecer, a princípio, do que sua obra irá ser. O que já está desvelado permite ao artista buscar o que ainda está velado. 


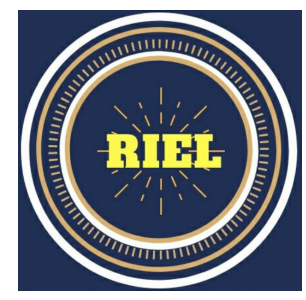

Assim, temos a obra desvelando-se diante do escritor. "Porque a verdade é mútua oposição de clareira e velamento" (HEIDEGGER, 2010, p. 157).

A existência é o estar sendo do dasein; assim somente o homem existe, os outros entes estão presentes. A compreensão da existência se dá de forma existenciária e/ou de forma existencial. A compreensão existenciária permite a compreensão do que já está dado, o que já está conhecido do dasein; já a compreensão existencial é a faculdade de entender o que ainda não se sabe, mas que é familiar. A personagem Macabéa se compreende de forma existenciária, por não buscar e nem questionar o seu ser: “Se tivesse a tolice de perguntar 'quem sou?' cairia estatelada e em cheio no chão" (LISPECTOR, 1998, p. 15). Ela se compreende de forma genérica o que ela supõe que é. Tem-se, desse modo, a compreensão existenciária que se dá de forma ôntica, ou seja, como algo que já está dado, formulado, conforme o trecho a seguir:

Essa moça não sabia que ela era o que era, assim como um cachorro não sabe que é cachorro. Daí não se sentir infeliz. A única coisa que queria era viver. Não sabia para quê, não se indagava. Quem sabe, achava que havia uma gloriazinha em viver. Ela pensava que a pessoa é obrigada a ser feliz. Então era. Antes de nascer ela era uma ideia? Antes de nascer ela era morta? Depois de nascer ela ia morrer? Mas que fina talhada de melancia.

[...] E quando acordava? Quando acordava não sabia mais quem era. Só depois é que pensava com satisfação: sou datilógrafa e virgem, e gosto de coca-cola. Só então vestia-se de si mesma, passava o resto do dia representando com obediência o papel de ser (LISPECTOR, 1998, p. 27-28 e 36).

Quanto à compreensão existencial, ela se dá por meio da busca, ou seja, através do questionamento do ser, por está longínquo e inapreensível, de forma ontológica, ou não muito distante, mas ainda inapreensível, que já lhe é familiar, uma forma (pré) ontológica, caso que ocorre com Rodrigo.

[...] Ainda bem que o que vou escrever já deve estar na certa de algum modo escrito em mim. Tenho é que me copiar com uma delicadeza de uma borboleta branca. Essa ideia de borboleta branca vem de que, se a moça vier a se casar, casarse-á magra e leve, e, como virgem, de branco. Ou não se casará? O fato é que tenho nas minhas mãos um destino e no entanto não me sinto com o poder de livremente inventar: sigo uma oculta linha fatal. Sou obrigado a procurar uma verdade que me ultrapassa. Por que escrevo sobre uma jovem que nem pobreza enfeitada tem? Talvez porque nela haja um reconhecimento e também porque na pobreza de corpo 
e espírito eu toco na santidade, eu que quero sentir o sopro do meu além. Para ser mais do eu sou, pois tão pouco sou (LISPECTOR, 1998, p. 21).

O compreender de si mesmo está ligado ao conceito de mundo. O dasein não se compreende de forma isolada, mas a percepção se dá em um mundo que lhe é familiar, ser-em um mundo (in-sein), e seu "destino" está diretamente ligado a esse mundo e aos entes que se desvelam dentro desse mundo (sein-in) que lhe é familiar.

A linguagem é para Rodrigo o seu mundo familiar. A compreensão da linguagem permitelhe dominá-la, já que dentro dela estão os entes palavras, conectados em entre si, e, quando estão em uso, passam a dar um significado além das próprias palavras, auxiliando-o na construção da narrativa e no desvelamento da obra. A partir da pequena abertura do ser e da obra, provocada pelo questionamento e o domínio da linguagem, permite a Rodrigo busca o que ainda está velado na escritura. Rodrigo compreende a si mesmo entrelaçado a esse mundo.

Mas que ao escrever - que o nome real seja dado às coisas. Cada coisa é uma palavra. E quando não se a tem, inventar-se-á. Esse vosso Deus que nos mandou inventar. Por que escrevo? Antes de tudo porque captei o espírito da língua e assim às vezes a forma é que faz conteúdo (LISPECTOR, 1998, p. 18).

Rodrigo está lançado nesse mundo sendo-com a linguagem e as palavras vêm ao seu encontro, dando-lhe um destino, não no sentido grego, mas na essência de antecipar a si mesmo e já sendo esse ser que ainda não é, é um projetar para além do ser lançado, “anteceder-a-si-mesma-nojá-ser-em..." (HEIDEGGER, 2012, p. 264), e aqui temos o dasein como cura. "Desculpai-me mas vou continuar a falar de mim que sou meu desconhecido, e ao escrever me surpreendo um pouco pois descobri que tenho um destino" (LISPECTOR, 1998, p. 15).

Como já dito, Macabéa não faz uso do questionamento do seu ser. Assim, está presa a um ser já dado pelo impessoal. Está lançada em um mundo que não lhe é familiar, e permanece nessa projeção sem um objetivo de ser, numa sociedade na qual não está inserida, não compreende o mundo, a facticidade que se constrói em seu ser-em um mundo familiar. Os entes dentro desse mundo estão desconexos, não tendo sentido algum. Eles não vêm ao encontro de Macabéa para que 


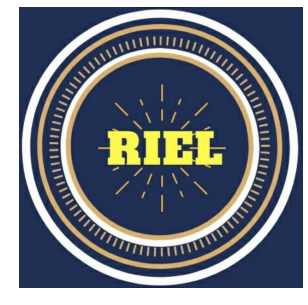

se possa compreender a si mesma e ao mundo. Em Rodrigo, os entes palavras se fazem presente, porém não se conectam a fim de dar um sentido além da própria palavra.

Uma das únicas coisas que compõem e possui um pobre sentido no mundo é a máquina de escrever, mas não há nela a decifração da linguagem. Também há um rádio relógio que lhe fornece parcas palavras, desconexas e sem aplicação útil.

As palavras não compõem o mundo de Macabéa. Elas não vêm ao seu encontro para darlhe significado. Assim ela não consegue antecipar a si mesma, sua compreensão de ser é estática, não consegue se projetar, para além do ser lançado. Dessa forma, não alcança a cura, conforme exemplo a seguir:

[...] Limito-me a contar a humildemente - mas sem fazer estardalhaço de minha humildade que já não seria humildade - limito-me a contar as fracas aventuras de uma moça numa cidade feita contra ela. Ela que deveria ter ficado no sertão de Alagoas com o vestido de chita e sem nenhum de datilografia, já que escrevia tão mal, só tinha até o terceiro ano primário. Por ser ignorante era obrigada na datilografia a copiar lentamente letra por letra - a tia é que lhe dera um curso ralo de como bater à máquina. Embora, ao que parece, não aprovasse na linguagem duas consoantes juntas e copiava a letra linda e redonda do amado chefe a palavra "designar" de modo como em língua falada diria: "desiguinar" (LISPECTOR, 1998, p. 15).

Em outro trecho:

[...] Nunca esqueceria que no primeiro encontro ele a chamara de "senhorinha", ele fizera dela um alguém. Como era um alguém, até comprou um batom cor-de-rosa. O seu diálogo era sempre oco. Dava-se conta longinquamente de que nunca dissera uma palavra verdadeira. (...) Na Rádio Relógio disseram uma palavra que achei meio esquisita: mimetismo (LISPECTOR, 1998, p. 54 -56).

Por conseguinte, o contraste entre Rodrigo e Macabéa é a própria linguagem. Ela não se faz presente em Macabéa. Não há o domínio dos entes palavras e muito menos compreende a si mesma e aos entes que compõem o seu ralo mundo. Já Rodrigo tem como ferramenta de trabalho a própria palavra em contraposição a Macabéa, que não consegue conectar uma palavra a outra. 


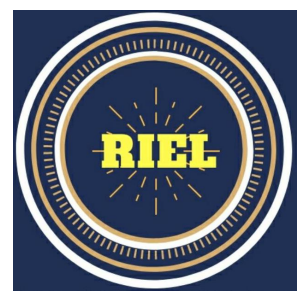

Macabéia trabalha como datilógrafa e escreve sobre assuntos que lhe são familiares. É a linguagem que permite o fazer literário e ir ao encontro do sentido do ser. São as palavras que vêm ao encontro de Rodrigo e se conectam ao seu mundo, dando um sentido maior à própria narrativa. Com o domínio da linguagem e o questionamento do ser, desvela-se a fenda da verdade na obra, onde o ser e o não-ser (nada) coexistem na busca do ser.

\section{CONSIDERAÇÕES FINAIS}

Os questionamentos levantados por Rodrigo o orienta para a verdade sobre a escritura, pois ainda não se sabe como a narrativa irá se desenvolver. Rodrigo está lançado no mundo da linguagem que lhe é familiar e se projeta para uma outra possibilidade de ser, antecipando a probabilidade. A cura se faz presente em sua existência, o ser e o não-ser (nada) coexistem na busca do que ainda não é, mas que se mostra como uma perspectiva de ser. A obra mostra-se independente de Rodrigo. Desvela pouco a pouco no labor literário por meio do questionamento e o que já foi desvelado o orienta para outra questão que possibilita outro desvelamento e a verdade da obra de arte se emergi do nada diante do escritor-narrador da obra corpus.

Macabéa por sua vez não tem um mundo familiar, como também a linguagem não lhe é familiar. Sua compreensão de ser e do mundo se limita a uma compreensão genérica das coisas, assim também se dá sua compreensão das palavras. O seu ser e a compreensão das coisas são estáticas e não possuem movimento, tendo uma projeção existenciária. Tanto Macabéa quanto Rodrigo estão rodeados de palavras, mas as palavras para Macabéa são soltas e não vão além delas mesma. Já para Rodrigo, as palavras se conectam, formando um significado além da própria palavra. Percebe-se que a linguagem é o seu mundo familiar, mas Macabéa nada lhe é familiar, tudo é desconexo tornando o seu mundo pouco familiar e "ralo" em sentido.

O que diferencia e torna visível o compromisso de Clarice Lispector, em fazer convergir a filosofia e a obra literária, é a possibilidade de questionar sobre o dilema estético e ético do ser-emsi. Em A Hora da Estrela (1998), o que vem à tona é seu poder de transbordamento da linguagem. A escritura se desprende facilmente de seus supostos e inexistentes autores. O autor é necessário no 
instante da criação. Em seguida, é preciso que essa primeira camada de pele se solte. Ano após ano as camadas de pele que uniam o autor a sua obra vão se despregando com maior facilidade. A última camada é o desvelamento que não se fecha mais, não se permite mais reconhecer este ou aquele sentido, antes facilmente reconhecível.

\section{REFERÊNCIAS}

AGAMBEN, G. O que é o contemporâneo e outros ensaios. Trad. Vinícius Nicastro Honesko. Chapecó, SC: Argos, 2010.

LISPECTOR, C. A hora da estrela. Rio de Janeiro: Rocco, 1998.

HEIDEGGER, M. A origem da obra de arte. Trad. Idalina Azevedo e Manuel Castro. São Paulo: 70 edições, 2010.

. Ser e Tempo. Trad. Márcia Sá Schuback. Petrópolis, RJ: Vozes, 2012.

INWOOD, M. Dicionário Heidegger. Trad. Luísa Buarque de Holanda. Rio de Janeiro: Jorge Zahar, 2002.

NIETZCHE, F. O nascimento da tragédia. São Paulo: Editora Escala, 2011.

PLATÃO. A República. São Paulo: Editora Martin Claret, 2007. 